\title{
E \\ Capital budgeting and flexible manufacturing
}

\author{
María J. Alvarez Gil*,1 \\ Departamento de Economia de la Empresa, Universidad Carlos III de Madrid Calle Madrid, 126, 28903 Getafe, Spain
}

\begin{abstract}
The lack of measurement and evaluation of flexible manufacturing possibilities seriously handicaps the appraisal and justification of investments in flexible technologies. It is the goal of this paper to formulate a comprehensive definition for manufacturing flexibility which can be explicitly translated into economic and financial variables. Further translation is based upon the financial instruments of cash budgeting and capital budgeting.

The sensitivity of the economic and financial variables to shifts in manufacturing/operational flexibility will be discussed from a theoretical point of view. It is concluded that operative variables for flexible technologies can become indicators of economic and financial aspects.
\end{abstract}

Key words: Manufacturing flexibility; Capital budgeting; Cash management; Advanced manufacturing technologies

\section{Introduction}

Considerations of improved productivity and production flexibility have assumed major importance in the design and operation of manufacturing systems. The globalization of competition has clearly underlined the need for greater manufacturing effectiveness. Moreover, shorter product life cycles, and greater product proliferation and market fragmentation indicate that manufacturing flexibility should be considered for the long-term viability of many firms [1].
It is well recognized that advanced manufacturing technologies (AMT) are not inherently profitable. Everything depends on their strategic selection and creative development. Large payoffs await companies willing to experiment with new managerial approaches to these technologies. Realizing the full potential of new computer-controlled design, production, and manufacturing planning and control requires developing (the knowledge of) the technical and infrastructural elements which create flexibility. This implies that the need to understand the sources and uses of flexibility has never been greater.

Although manufacturing flexibility has generally been recognized as an important competitive weapon in operations management (OM) [2], it seems that the concept itself has not yet been clearly understood in the industry [3]. If this is so, or if its 


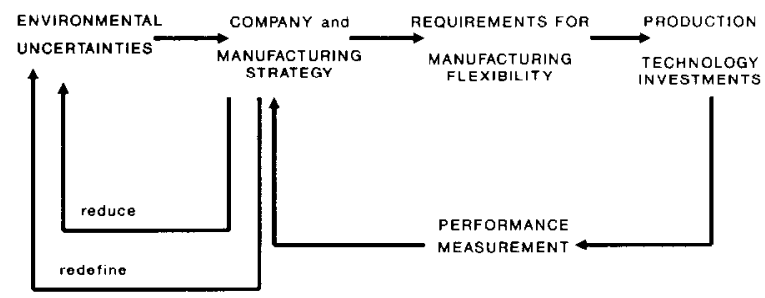

Fig. 1. Conceptual framework - links between strategy and flexibility.

value cannot be ascertained in a way that is meaningful to operations management, it is less likely to be incorporated into the OM strategy [4].

To explore the links between strategy and flexibility, it is useful to work within a broad context $[5$, p. 22$]$, as suggested by the conceptual framework illustrated in Fig. 1. This framework is a modified contingency model that came forward from organization theory and manufacturing strategy literatures $[6,7]$. Manufacturing strategy and investments in production technology, such as in AMT, are related by virtue of their interactions with environmental uncertainties, manufacturing flexibility and performance measures. The driving force is an organization's task environment; management has to learn to cope with uncertainties arising in the product market or in the production process and its inputs. Managerial learning is reflected in a manufacturing strategy that tries to adapt to the uncertainties and/or attempts to control uncertainties proactively [8]. Manufacturing flexibility is needed to adapt to uncertainties; it allows a corporation to respond effectively to changing circumstances [9].

In the above conceptual model, any need for flexibility is supposed to be met through capital investment in production technology, thus making the design and justification of AMT a salient issue. However, this does not imply that other means cannot be used to create flexibility, for instance by product design, subcontracting, work organization, materials management and so on.

A majority of plant managers identity flexibility as a critical task for future competitiveness [10]. However, none of the plants included it among their top three formally tracked objectives for planning and control. This observation was reconfirmed by the research conducted in 1987 by The Manufacturing Roundtable of Boston University [11]: flexibility was ranked from fourth to eighth (depending on the industry) in importance for future competitiveness, and first in the size of the strategic gap (i.e., the difference between current capability and future needs). Typically, flexibility did not appear at all in a list of ten key performance measures. The 1990 Boston University Manufacturing Futures Survey [12] also confirms it. Two explanations were proposed for the discrepancy between the strategic role of flexibility and the little, if any, attention paid to the development of flexibility performance measures. First, in contrast to cost, delivery and quality, which have heen the cornerstones of manufacturing planning and control for many years, flexibility as a top priority has only recently come to the fore. Consequently, even on a conceptual level, it tends to be discussed relatively less often and, if discussed, usually on a somewhat abstract basis. Second, and linked to the first argument, the technology for measuring flexibility is poorly developed. That is, in spite of its importance, flexibility is rarely explicitly measured and is often excluded from the operational control systems of manufactures. From these observations, it is concluded that there is a strong necessity to develop a measure of manufacturing flexibility, both conceptually and operationally [10].

The problem of understanding and measuring manufacturing flexibility has received considerable attention in recent years. Further research has pointed out that major hurdles to our understanding of manufacturing flexibility are the lack of a consensus on the terms used to describe flexibility [8]:

(i) the scope of flexibility related terms used by various authors overlap considerably;

(ii) some Hexibility terms are aggregates of other flexibilities terms:

(iii) identical flexibility related terms used by more than one author do not necessarily mean the same thing.

A large number of studies have looked at the various types of flexibility in manufacturing systems and have proposed different approaches to measure it. In an extensive survey of the studies on 
the issue of flexibility in manufacturing [13], it was observed that at least 50 different terms for various types of flexibilities can be found in the manufacturing literature and that several terms are used to refer to the same type of flexibility.

The multitude of flexibility measures contributes a great deal to our understanding of the multidimensional nature of manufacturing flexibility [4]. However, many of the measures suffer from the following limitations:

(1) They are non-financial measures, except for a few in which dollar values have been suggested for the shadow prices of resources or for product switching costs.

(2) They are local measures, i.e. they look at only a few dimensions of manufacturing flexibility and thereby ignore possible trade-offs that may exist between the different dimensions.

(3) They are isolated measures, i.e. they are formulated independent of the environment in which the manufacturing system functions.

A further complicating factor, these authors comment, is the fact that an appropriate time horizon must be specified to measure the value of any type of flexibility. It is thus evident that it is perhaps impossible to find a general measure of flexibility that captures its value along all dimensions and that is appropriate over all time horizons.

Although there is as yet no complete consensus on the definition of the dimensions of manufacturing flexibility, insight has advanced to the point where the focus of research on flexibility should shift [14]. However, much less has been done to make these measures operational $[15,16]$.

So far, there is an imperative need to ascertain the value of the flexibility of a manufacturing system as a whole; this value has to be stated in such a way that managers can appraise and justify the flexible technology investments. With this need in mind, it is the goal of this paper to propose (1) a value-based approach for the measurement of a manufacturing system's flexibility which focuses on the manufacturing variables that are particularly relevant in the economic and financial justification of manufacturing flexibility; this approach will consider both long-term and short-term manufacturing/operative and financial variables, and (2) an early warning system for the study and sensitiv- ity analysis of the financial and economic variables to shifts in manufacturing flexibility.

The remainder of this paper is organized in the following manner: First I characterize the specific nature of the manufacturing flexibility that is being evaluated and identify the different types of flexibility that are included in this characterization. A capital and treasury budgeting-based approach is then proposed to measure and justify the investments in flexible technology. A numerical example is developed to provide some guidance on the translation process of the manufacturing variables into economic and finance variables, and to illustrate how the suggested approach works. Next, an early warning system is suggested that can be used to forecast the financial impacts of the different manufacturing flexibilities. Finally, a summary and some concluding remarks are provided.

\section{Flexible manufacturing: operative variables (characterization and measure)}

The starting point for the development of a value-based approach to the measurement of the flexibility are studies by Gupta and Somers [17] and Sethi and Sethi [13]. This approach will simplify the financial justification of flexible manufacturing technologies investments. According to the outcomes of the study by [17, pp. 170-171], it can be suggested that the manufacturing flexibility is a compound of the following flexibilities.

Machine flexibility deals with a variety of operations that a machine can perform without incurring high costs or using prohibitive amounts of time in switching from one operation to another. Machine flexibility allows small batch sizes which, as a result, result in lower inventory costs, higher machine utilizations, ability to produce complex parts, and improved product quality.

Material handling flexibility is defined as the ability of material handling systems to move different part types effectively through the manufacturing facility, including loading and unloading of parts, intermachine transportation and storage of parts under various conditions of manufacturing flexibility. In the end, material handling flexibility may 
increase machine availability and reduce throughput times.

Process flexibility is defined as the ability of a manufacturing system to produce a set of part types without major set-ups, which is sometimes referred to as mix flexibility $[18,19]$. Process flexibility is useful in reducing batch sizes and, as a result, inventory costs. Since it allows the sharing of machines, it minimizes the need for duplicate machines.

Product flexibility is defined by the ease with which new parts can be added or substituted for existing parts, i.e. the ease with which the current part mix can be changed at relatively low cost in a short period. Product flexibility helps the firm to be market responsive by enabling it to bring newly designed products quickly to the market.

Routing flexibility refers to the ability of a manufacturing system to produce a part by alternate routes through the system. The purpose of routing flexibility is to continue to produce a given set of part types, albeit at a lower rate in the event of unexpected machine breakdown. It allows efficient scheduling of parts via improved balancing of machine loads.

Volume flexibility is the ability of a manufacturing system to be operated profitably at different overall output levels, thus allowing the factory to adjust production within a wide range.

Expansion flexibility is the extent to which overall effort is needed to increase the capacity and capability of a manufacturing system. Expansion flexibility may help shorten implementation time and reduce cost for new products, variations of existing products, or added capacity.

Programming flexibility is the ability of the system to run virtually unattended for a long enough period. Programme flexibility reduces the throughput time via reducing set-up times, improving inspection and gauging, and better fixtures and tools.

Production flexibility is the universe of part types that the manufacturing system can produce without adding major equipment. This type of flexibility is dependent on several factors such as variety and versatility of available machines, flexibility of material handling systems, and factory information and control systems.

Market flexibility can be detined as the ease with which the manufacturing system can adapt to changing market environments. It allows the firm to respond to changes without seriously affecting the business and to enable the firm to outmanoeuver its less flexible competitors in exploiting new business opportunities.

Gupta and Somers' study deals with the development of a standard measure of manufacturing flexibility. The authors analyse, by means of the factor analysis technique, how the different items measuring manufacturing flexibility have been incorporated by the literature; they sum up 34 items, explaining the different types of flexibility suggested by [13] and their relative relevance for companies. This standard measure of manufacturing flexibility only considers 21 items from the above 34 . The 21 manufacturing variables to be considered in the model are described in the following terms:

A time required to introduce new products is extremely low

D time required to add a unit of production capacity is low

E shortage cost of finished products is extremely low

F cost of delay in meeting customers orders is extremely low

$G$ size of the universe of parts the manufacturing system is capable of producing without adding major capital equipments is extremely large

$\mathrm{H}$ the manufacturing system is capable of running virtually unattended during the second and third shift

I cost of doubling the output of the system is likely to be extremely low

$\mathrm{J}$ time that may be required to double the output of the system is likely to be extremely low

$K$ the capacity of the system can he increased when needed with ease

L the capability of the system can be increased when needed with ease

$\mathrm{N}$ the range of volumes in which the firm can run profitably is extremely high

$P \quad$ cost of the production lost as a result of expediting a preemptive order is extremely low

$Q$ decrease in throughput because of a machine breakdown is extremely low

$S$ number of new parts introduced per year is very high 


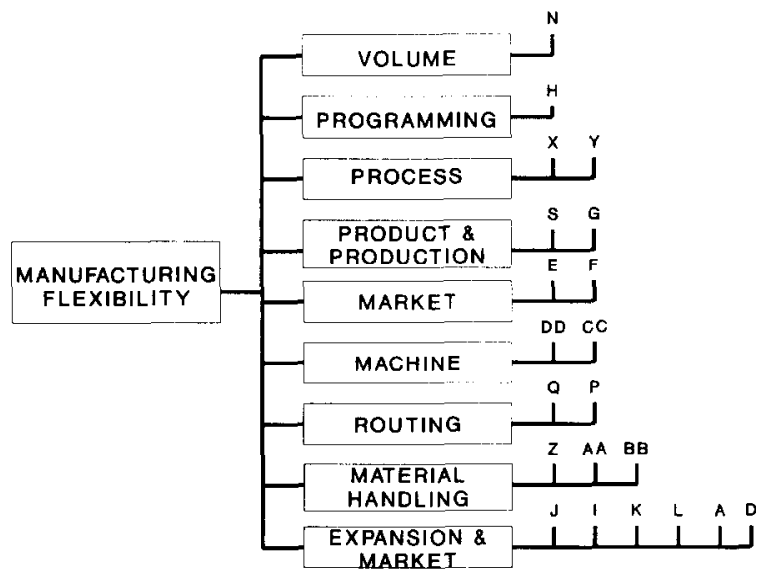

Fig. 2. Model for measuring manufacturing flexibility.

$\mathrm{X}$ changeover cost between production task within the current production programme is extremely low

$\mathrm{Y}$ the ratio of the total output and the waiting cost of parts processes is extremely low

$Z$ the ability of material handling system to move different part types for proper positioning and processing through the manufacturing facility is extremely high

AA the ratio of the number of paths the material handling systems can support to the total number of paths is very high

BB the material handling system can link every machine to every other machine

$\mathrm{CC}$ the number of different operations that a typical machine can perform without requiring a prohibitive time in switching from one operation to another is very high

DD the number of different operations that a typical machine can perform without requiring a prohibitive cost in switching from one operation to another is very high

According to the outcome of the study by [17], it can be suggested that the manufacturing flexibility is a compound of the following flexibilities:

- expansion and markets flexibilities;

- volume flexibility;

- product and production flexibilities;

- market flexibility;

- machine flexibility; process flexibility;

- programming;

- routing; material handling flexibility.

See Fig. 2 for an illustration of Gupta and Somers' model.

In order to translate the above-mentioned manufacturing/operative variables into financial variables, it is necessary to identify first the types of flexibility which have relationships with various decisions [20]. This can be achieved by classifying the types of flexibilities according to their impact on long-term and short-term decisions [20]. Conventionally, long-term decisions are financially associated with long-term capital budgeting, while short-term decisions are associated with cash management and treasury budgeting.

Long-term decisions concerning flexible technology acquisitions are strategic decisions and involve substantial investments. They relate to design flexibility and are concerned with the decisions that must be made before installation of the system/technologies. This flexibility reflects, or should reflect, the needs for flexibility directly derived from the strategy of the firm with reference to its markets (see Fig. 1). Accordingly, it relates to the capacity of the production technology to introduce changes in the product mix, in the design, and in the scope of new products and new products generation [21]. So far, design flexibility refers to the ability to vary production across a greater range of volumes; to attain faster a new production level within its volume range; to increase the breadth of the product line; the extent of product variety, etc.

Coming back to Fig. 1, design flexibility would influence the strategic type of production technology investments that a firm should accomplish. Short-term decisions concerning flexible technology implementation and control are involved with the operation of the plant and linked to operational flexibility [21]. This operational flexibility relates to the capability of the equipment/production process/plant to respond on time to changes in plans, programmes and schedules, within the requirements set by the operations strategy, and thus influencing the performance of the firm. (See Fig. 1).

Thus, although both types of flexibility are tied closely and are interdependent, they refer to 
complementary stages in the appraisal of the new production technology investments process: design flexibility has to be incorporated into the assessment, justification and financing of the investment (ex-ante justification), while operational flexibility has to be taken into account for the monitoring and control of performance (ex-post justification).

It is assumed that investments leading to a higher design flexibility should be appraised as long-term capital investments given the nature and content of such flexibility. This implies that (1) capital budgeting techniques are suitable for their financial justification and that (2) a linkage has to be made between the financial variables used by those techniques, and the manufacturing variables measuring the strategic or long-term performance of the flexible investments. It is also assumed that financial monitoring and control of these investments should be performed by cash budgeting and control techniques, i.e. a second linkage has to be established between the financial short-term variables and the operative or manufacturing variables measuring the daily performance of the flexible investments. i.e. the operational flexibility. ${ }^{2}$

This distinction between long and short-term flexibilities and capital and cash budgeting techniques will allow the ex-ante and ex-post justifications of investments in flexible equipments. It tries to show in an easy way the likely consistency between the measures of the productions process and the organization's actions and strategies. According to Nanni's comments [29, pp. 7 and 8], and the fact that senior management will more readily accept a new radical technology if it is justified on familiar grounds rather than with a completely new approach, simplicity has been pursued: the classification proposed here focuses attention such that there are enough measures to reveal and solve critical problems, but not so many as to create confusion.

Design flexibility provides data that helps to calculate the net present value (NPV), the internal

\footnotetext{
2 There is a big controversy on the suitability of conventional capital budgeting techniques for the advanced manufacturing technology investment appraisals. The main pitfalls of DCF's procedures have been widely discussed, see for instance [22-28].
}

rate of return (IRR), or any other capital budgeting index. If the strategy of the firm is to acquire flexible equipments, one action to perform will be to determine its economic and financial feasibility. Operational flexibility provides data on whether the strategic objectives are successfully completed, the manufacturing activities are being done wastefully or not, and on the way the firm is organized to do these activities.

The next step is to identify those manufacturing or operative variables related to design flexibility and those related to operational flexibility. Most of the firms that have already acquired flexible technologies have employed conventional justification techniques like NPV or IRR, ${ }^{3}$ and the tangible and quantifiable benefits of the new technology have been taken into account. These benefits are summarized as [32, pp. 205]

- increased market share;

- increased sales volume;

- increased production volume;

- successful development of new products;

- reduced product development time;

- development of new markets;

- fewer customer complaints;

- reduced defect costs and reduced scrap costs;

- shortening of delivery time;

- direct labor savings;

- reduced work-in-process and finished-goods inventory levels;

- reduced floor space requirements;

- improved product quality leading to reduced inspection, rework, scrap, warranty, and service costs;

- reduced tooling, utilities, maintenance, production control, fixturing, and material costs.

The economic value of these benefits can be known with certainty or at least up to a probability distribution. According to [5, pp. 52] this type of benefits can be categorized as "zero-order intangibles". For the purpose of this paper, the ex-ante quantification of these benefits are well suited. If a direct linkage can be found between the above benefits and the nine flexibilities suggested by Gupta and Somers

\footnotetext{
${ }^{3}$ See the empirical evidence provided by $[22,30,31]$
} 


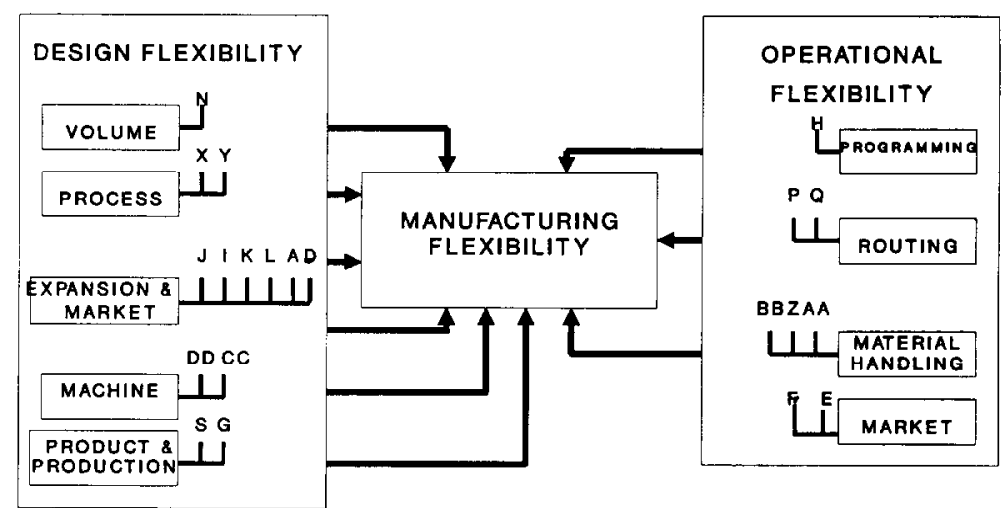

Fig. 3. Proposed model for measuring manufacturing flexibility.

[17, pp. 17], then a group can be formed that relates to design flexibility. Equally, a second group can be formed relating to operational flexibility. The latter will include all flexibility types that are not linked to the above benefits. Consequently, this second group contains a limited chance, if any, to estimate ex-ante their tangible benefits. As a result, the second operational flexibility group can be considered to comprise all intangible benefits, which can be summed as [32, pp. 205]:

- increased product uniformity;

- increased ability to quickly enter new markets;

- increased goodwill generated through the new reputation the firm acquired;

- synergy with other equipment;

- better scheduling/workflow;

- increased strategic options and reduced risk of obsolescence;

- improved product quality leading to improved market image;

- ability to respond quickly to future technology advances;

- offset technology adoption by competitors;

- increased employee morale;

- better customer service;

- reduced training and supervision;

- increased utilization of manpower and equipment; reduced expediting;

- reduced materials handling;

more disciplinated manufacturing process;

- increased safety.
According to the definitions given for the nine different types of flexibility and their direct relationship with the tangible benefits, the design flexibility category will consist of the following types:

- machine flexibility,

- process flexibility,

- product and production flexibility,

- volume flexibility and

- expansion and market flexibility.

The operational flexibility category will include: material handling flexibility,

- routing flexibility,

- programming flexibility and

- market flexibility. ${ }^{4}$

The proposed classification gives way to a modified version of Gupta and Somers [17] model. This proposed modified version is illustrated by Fig. 3 .

\footnotetext{
${ }^{4}$ It is assumed that direct linkages can be traced between routing, programming, market, and material handling flexibilities and those benefits classified as intangible ones [32] or, as

- "first-order" intangibles, i.e. those whose economic value is not quantifiable but can be readily stated in physical terms with certainty or by using probabilities,

- "second-order" intangibles which are nonpecuniary factors that can be enumerated but are not measurable in physical terms except perhaps on a qualitative basis,

- "third-order" intangibles which represent factors producing unanticipated benefits and costs that are typically not measurable [5, pp. 52].

In this regard, it can only be assumed that these intangible benefits properly fit the ex-post justification of the flexible technology investment.
} 


\section{Flexible manufacturing and capital budgeting}

Once the flexibility identification has been completed, both types of manufacturing flexibility (design and operational) variables can be linked to corresponding financial variables, thus leading to the translation of operative measures, i.e. the 21 manufacturing variables identified by [17], into financial and economic measures.

Investment in flexible manufacturing equipment is expected to modify the design and/or operational flexibilities of the investing company. No matter how relevant these changes can be for that firm's survival, if they are not financially justified, the investment will not get the approval and the go-ahead; the justification process is largely strategic in nature but must also involve finance issues.

Consequently, the main objective of the translation system proposed here will be to provide both financial and operations managers with a tool that indicates them:

- which of the operative variables explaining design flexibility may modify the estimates of the long-term capital budgeting variables (see Fig. 3),

which of the operative variables explaining operational flexibility may vary the estimates of the short-term cash and treasury budgeting and management variables (see Fig. 3).

Once this correspondence is defined, the next step will be to develop a procedure to determine when such linkages should be considered in the NPV and/or IRR computations and how. This will be done in Section 4.

\subsection{Design flexibility and capital budgeting techniques}

Capital budgeting techniques, such as the NPV or the IRR, are often used for capital investments appraisals. They concentrate in the appraisal of long-term assets being mainly financed with longterm funds. The financial variables used by these techniques are initial investment outlay, expected cash flows, residual or salvage value and discount rate. These variables are the ones which have to be linked to operative variables associated with design flexibility. ${ }^{5}$

The initial investment outlay information to be gathered refers basically to the acquisition cost of the new production capacity, with the acquisition cost depending upon both the time needed for the completion of this new capacity, and the alternate uses of such capacity. Next, what needs to be estimated is the incremental initial investment outlay, which can be computed as the initial investment outlay needed for the "rigid" (i.e. non-flexible) technologies minus the investment outlay referring to flexible technologies or vice versa if the initial investment needed for the flexible technology is higher than the one required by the "rigid" technology acquisition.

The proposed model assumes that machine, process, production and product, volume, and expansion and market flexibilities associated with both flexible and rigid technologies, may help in the assessment of their acquisition cost, as well as the time needed for the achievement of new production capacity and the alternative uses of such capacity. These flexibilities can provide insightful information on the variety of products and volumes that the firm may offer, thus indicating which markets can be served. According to the outcome of the study by [17], these types of flexibilities are explained by the manufacturing variables $\mathrm{DD}, \mathrm{CC}$ (machine), $X, Y$ (process), $S, G$ (production and product), $N$ (volume), and $J, I, K, L, A$, and $D$ (expansion and market) (see their definition in the previous section of this paper and Fig. 2).

Apart from depreciable assets, the investment in flexible technologies, as any other type of investment, often requires an investment in the working capital. The financial items underlying working capital relate to the current dealings of the organization [33]. In general, it is depicted as a cycle, tied to the operating cycle of production [26]. It is in

\footnotetext{
${ }^{5}$ As is previously stated, this proposal is aware of the many pitfalls of DCF procedures. The main goal of the suggested approach is to provide management with more accurate and operative-oriented data so that they can avoid some of the inherent weaknesses of the cash and capital budgeting techniques.
} 
this operating cycle that some types of design flexibility (process flexibility) and operational fiexibility, (programming, routing and material handling flexibilities), relate to working capital, having their effects mainly on cash outflows.

The question to assess then is how investments in a working capital associated with flexible technologies, differ from those of rigid technologies investments, so that the incremental working capital (being positive or negative) can be estimated. According to our flexibility definition (see Section 2), operational flexibility may lead to reduced through put times via a reduction of the set-up times, the continuity of the production process and the increase of the machine availability. This may lead to lower work-in-progress inventories [5, pp. 21-42]. Process flexibility (included in the design flexibility group) also contributes to lower work-in-progress inventories, because it is useful in reducing batch sizes and, in turn, finished goods inventories [5, pp. 21-42]. Equally a lower amount of current assets can be expected, other balance sheet related accounts remaining unchanged, giving way to a decreased need of working capital. The manufacturing variables to be analysed will be $X, Y$ (process), $H$ (programming), $Q, P$ (routing), and $Z, \mathrm{AA}, \mathrm{BB}$ (material handling). (See Fig. 2 again.) Reliable estimates of the incremental need of working capital will not be available until a first manufacturing cycle has taken place. Since more reliability is advisable, the estimates should be made ex-post, i.e. once the new flexible equipment has been acquired and implemented. Nevertheless, this does not imply that ex-ante estimations will not have to be performed. For example, additional long-term capital funding could be needed for the first new manufacturing cycle or, vice versa, financial resources can be freed and, thus, employed for alternative purposes [34]. At minimum, aggregate estimates are revised on a yearly basis, and information provided by operational flexibility can be of significant help, as will be discussed in a later section of this paper.

Design flexibility may significantly influence the expected cash flows. Once again, the relevant information is tied to the differences between the expected cash flows of the firm when employing rigid technology (the "base case") and the expected cash flows due to the use of flexible technology.
Typically, data to take into account refer to the expected increments in sales, costs of goods sold, and operating expenses. It can be assumed that all flexibilities explaining the design and operational flexibilities are likely to influence the cash-flows figures. However, for the ex-ante calculations, data will only be available on the manufacturing variables explaining design flexibility. Revised estimates of the actual cash-flows figures will be influenced by operational flexibility related data. It means that for incremental NPV and/or IRR calculations, manufacturing variables to be considered will be the ones related to design flexibility, i.e. $\mathrm{DD}, \mathrm{CC}$, (machine), $X, Y$ (process), $S, G$ (production and product), $N$ (volume), and $J, I, K, L, A$ and $D$ (expansion and market). (See their definition in the previous section of this paper and the linkages illustrated in Fig. 2).

The incremental initial investment outlay - acquisition costs plus or minus the working capital needed - equals the incremental funds that will need to be sourced. During the expected life of the new flexible equipment to be acquired, funds can be provided by the potential increase in self-financing, to be obtained if higher incremental cash flows (after taxes) are expected to occur and the dividend payout and non-distributed benefits policies remain unchanged. As a result, the amount of external funds needed can be lower, which in turn may influence the cost of capital. Therefore, the discount rate to be used for the NPV computations should be equal to the cost of capital for the incremental funds.

It is difficult to estimate the future residual or salvage values of flexible technology, as well as assessing the gap between continuing to use rigid technology equipment and flexible technology. It is assumed that the depreciation of machines can be estimated from their usage rate, and thus their residual value; aggregate estimates can be obtained by considering the design flexibilities. ${ }^{6}$ The manufacturing or operative variables to be analysed will

\footnotetext{
${ }^{6}$ By definition, higher design flexibility allows higher usage rates provided there is a higher uncertainty in the demand side. Nevertheless, for accurate (and ex-post) estimates, data on the operational flexibility of the investment should be used.
} 
be CC, DD, $X, Y, S, G, N, J, I, K, L, A$ and $D$ (see their definition in the previous section).

\subsection{Linking design flexibility variables and capital investment appraisal ones: main assumptions and an illustrative example.}

Given that a company might not be interested in achieving any kind of manufacturing flexibility and since companies usually have a budgetary constraint and they are more or less forced to achieve a given level of profitability, some questions have to be answered before a new equipment is acquired. Different and independent flexibilities provided by any new equipment have to (1) be suitable for serving the company's market and to react adequately to changes in that market, (2) fulfill the budgetary constraint, and (3) fulfill the profitability constraints.

So far, the company has to identify first the main features of the market it is serving. These features relate to variables like the requested amount, price and types of products, the accepted level of quality, admissible delivery time, and so on. According to these characteristics, the company has to identify which equipment or equipments, among the many ones in the market, provide the different degrees of design flexibilities that are more suitable to gain a competitive advantage in the company's market. Flexibility variables to take into account are DD and $\mathrm{CC}$, machine flexibility; $X$ and $Y$, process flexibility; $N$, volume flexibility; $J, I, K, L, A$ and $D$, expansion and market flexibility. More relevant information to be gathered here relates to the production capacity, i.e. the number of new products which can be introduced if they are demanded, maximum and minimum total output which can be produced if required, maximum and minimum achievable delivery time, etc. It is assumed that the above-mentioned variables are independent and so are their effects.

The selected equipment or group of equipments will then have to be analysed to determine if it (they) fulfill the budgetary constraint. The equipment or equipments which satisfy this constraint will then be assessed in order to identify which of them satisfies the profitability constraints. Once the linkages between design flexibility variables and capital investments appraisal ones have been cstablished (see Section 3.1), the next step will be to develop a mechanism which allows for the translation of the design flexibility variables into "monetarized" variables. These "monetarized' variables will be used for the calculations of the corresponding NPV and/or IRR values, thus leading to the selection of the equipment which satisfics better the profitability constraints.

The mechanism here suggested relies upon the main assumption that any kind of manufacturing flexibility might be translated into a percentage of the operative costs incurred for manufacturing a product or a family of products. What this means is that the potential manufacturing advantages provided for the design flexibility are not free, and, accordingly, if a firm wishes to become flexible in the manufacturing sense, it will incur an additional cost, which has to be assessed.

It is here that the definition of the manufacturing flexibility variables selected by Gupta and Somers comes to the fore: most of them are described in terms of cost and time needed to increase the flexibility of a production system. What has to be done now is to calculate these costs and times, and translate time's figures into costs ones.

This is not an easy process since costs and time figures are closely tied to variable amounts of potentially produced output. This implies that linkages have to be traced between units of output and time and cost figures. For example, when dealing with the manufacturing flexibility variable $F$ (cost of delay in meeting customers orders is extremely low), different cost figures should be considered for different sizes of delays, i.e. if there is a delay of 50 units of a given item, the cost of the delay will be $Y$ dollars, while if the delay sizes 100 units, the cost will be $Y+Z$, where $Z \ll Y$. If the variable to consider is $S$ (number of new parts introduced per year is very high), the possible different numbers of parts have to be estimated and costs for the different numbers have to be calculated; for example, producing 20 different parts will amount for a cost of $X$ dollars, while producing 40 different parts will sum up $2 X-10$ dollars. For variable $J$ (time that may be required to double the output of the system is likely to be extremely low), the required time has 
to be assessed not only for the double output, but for smaller quantities as well, and these required times have to be translated later into associated costs figures.

Flexibility variables which have to be monetarize are DD and CC, machine flexibility; $X$ and $Y$, process flexibility; $N$, volume flexibility; $J, I, K$, $L, A$ and $D$, expansion and market flexibility.

This procedure requires a joint effort from accountants and operations managers, which will have to share information and to elaborate cost standards for the different degrees of flexibility provided for the flexible equipment to acquire. The more accurate estimates they provide, the more reliable estimates to incorporate to the investment appraisal process and, therefore, more reliable values for NPV and/or IRR.

The following numerical example has been developed to illustrate how the described process may help a firm in assessing and selecting of the most suitable equipment to be acquired.

Company $\mathrm{X}$ is a Spanish firm which is having trouble with its market share. It is the belief of its top management that this situation may improve if the production process is modified by means of the acquisition of new equipment. The market which this company serves demands item A, admits some percentage of rejected items per order, $25 \%$, and the normal accepted delivery time per order is 6 days. Demand for item A during the past three years has been variable; according to marketing managers, it consisted of 180 units in $25 \%$ of the cases, 200 in $50 \%$, and 220 in the remaining $25 \%$ of the cases. Companies' gross margin per unit for this sector is 4 monetary units. The current interest rate is supposed to be $10 \%{ }^{7}$ Company $\mathrm{X}$ has a limited

\footnotetext{
${ }^{7}[22,30,31]$ provide empirical evidence related to this point and the time horizon to consider:

- The surveyed UK companies permit a longer payback time for AMT investments, this way contradicting the suggestions made by some commentators that, owing to the perceived level of risk, shorter required paybacks are usually set by investing companies.

For the same companies, very little difference emerged between the rate of interest applied to AMT and non-AMT investments, which may imply that there is a negligible difference between the perceived decrease in the risks of the forms of investment when discount rates are applied. There is no
}

and small budget, accounting for no more than 2000 (monetary units). The acquired equipment will be used during the next $3 \mathrm{yr}$, after which the factory will be dismantled.

There are two equipments available for the company that suit the budget:

- the "conventional" model, which is relatively flexible, with a price of 1400 monetary units, and

- the "advanced" model, which is more flexible according to operations managers, with a price of 1700 monetary units (these prices only refer to the acquisition cost of the equipment).

Technical features for both equipments are as follows

\section{Conventional model}

Under standard conditions, the production rate for this model is 200 units of item A, upper and lower production rate levels being 250 and 150 units, respectively. It provides a quality level of rejected items of $25 \%$, but this level can be modified; the minimum rate of rejected items can be $10 \%$, while the maximum can amounts to $35 \%$. Although its standard delivery time is 6 days per order, it can be decreased to 4 days. This equipment is also suitable for the production of a new product, B. Thus, its standard process time could be shared by both products, but no more than the $70 \%$ of the total process time can be dedicated to manufacture product B.

Deviations from the designed current configuration bring together an increase in the operative costs, leading to a reduction of the gross margin per unit. Deviations and their associated operative costs are shown in Table 1.

(If the demand happens to be 220 units, the current configuration would be readjusted to produce this quantity, which represents an increase of $10 \%$ in the standard production rate. Since this equipment only allows an increase or decrease of $20 \%$, the cost effect for each unit of item produced would be a $4 \%$ decrease in its gross margin. If the delivery time demanded by customers decreases to

\footnotetext{
evidence from the surveys to support the popular assertion that excessive discount rates are used for AMT investments. An interest rate of $10 \%$ is reasonable for the Spanish capital market and the time horizon that companies use to consider varies between 3 and 4 years.
} 
4 days, the standard time will have to be decreased by $34 \%$, which reduces the gross margin per unit by $20 \%(30 \%<34 \%<40 \%$, then cost increase in $0.05 \times 4)$.

\section{Advanced model}

Under standard operative conditions, it can manufacture 210 units, with upper and lower levels being 273 and 147 , respectively. The quality level is fixed at a rate of $10 \%$ rejected items. This competitive advantage has a fixed cost, which leads to a $3 \%$ decrease in gross margin per unit, no matter what the level demanded. The standard delivery time is the shortest in the market: 4-8 days. The company will have to pay for this feature a fixed amount of $2 \%$ of the gross margin. It can be decreased at no additional cost to a minimum of 3.84 days if required. It is also possible to produce item B if it is demanded by customers, the maximum total process time dedicated to $\mathrm{B}$ not being superior to $80 \%$.

Once again, deviations from the standard rates diminish the gross margin per produced unit. Deviations and their associated costs are shown in Table 2. According to the technical features and acquisition costs of both equipments, any one of them is suitable for the purposes of the company.
After applying the NPV technique - assuming the market would remain the same as it is now for the next three years, and that demand can be well described by its expected mean, like in Hillier's model [35] - the acquisition of the "conventional" model seems to be better, since its associated NPV is higher than the "advanced" model one.

However, top management does not believe the rejection of the acquisition of the "advanced" model to be advisable, given that the market of the company is becoming increasingly turbulent, with changes not only in the demand levels, but in quality, and delivery times as well. Furthermore, it is expected that demand for product B will grow. They assume that operative and competitive status of Company $\mathrm{X}$ will undoubtedly change in the near future. Under these assumptions, the decision is reconsidered, and more realistic scenarios for the production and sales plan are taken into account. These scenarios are provided by the company's marketing experts, and the outcomes of their detailed study are the following forecasts:

(a) Demand fluctuations: The expected total demand for the next three years will take the following values: 180,210 and 240 with associated probabilities of $35 \%, 40 \%$ and $25 \%$, respectively.

Table 1

The conventional model: flexibilities and associated costs

\begin{tabular}{|c|c|c|c|c|}
\hline Deviations & $\begin{array}{l}\text { Demand } \\
\pm 20 \% \text { of standard } \\
\text { production rate }\end{array}$ & $\begin{array}{l}\text { Quality } \\
\pm 10 \text { points of the } \\
\text { standard quality level }\end{array}$ & $\begin{array}{l}\text { Delivery time } \\
\pm 10 \% \text { of the standard } \\
\text { delivery time }\end{array}$ & $\begin{array}{l}\text { Products range } \\
\pm 20 \% \text { of the total process } \\
\text { time dedicated to product } A\end{array}$ \\
\hline $\begin{array}{l}\text { Associated } \\
\text { costs (Decrease in } \\
\text { the gross margin } \\
\text { per unit) }\end{array}$ & $4 \%$ & $7 \%$ & $5 \%$ & $15 \%$ \\
\hline
\end{tabular}

Table 2

The advanced model: flexibilities and associated costs

\begin{tabular}{|c|c|c|c|c|}
\hline Deviations & $\begin{array}{l}\text { Demand } \\
\pm 10 \% \text { of slandard } \\
\text { production rate }\end{array}$ & $\begin{array}{l}\text { Quality } \\
\text { Level fixed } \\
\text { at } 10 \%\end{array}$ & $\begin{array}{l}\text { Delivery time } \\
\pm 20 \% \text { of the standard } \\
\text { delivery time }\end{array}$ & $\begin{array}{l}\text { Products range } \\
\pm 20 \% \text { of the total process } \\
\text { time dedicated to product A }\end{array}$ \\
\hline $\begin{array}{l}\text { Associated costs (Decrease } \\
\text { in the gross margin per unit; } \\
\text { penalties for higher quality } \\
\text { Icvels and shorter delivery } \\
\text { times are not included) }\end{array}$ & $3 \%$ & & $2 \%$ & $3 \%$ \\
\hline
\end{tabular}


(b) Quality levels: The rejection rate will decrease, taking values between $15 \%$ and the current $25 \%$. Most likely estimates are $15 \%, 20 \%$ and $25 \%$, with associated probabilities of $25 \%$, $40 \%$ and $35 \%$, respectively.

(c) Delivery time fluctuations: Increased competition is expected, leading to consecutive reductions. Most likely estimates are 6.5, 5.5 and 4.5, with associated probabilities of $15 \%, 55 \%$ and $30 \%$, respectively.

(d) Demand consolidation for product B: Product $B$ is superior to product $A$, which may lead to a change in the demand of product $A$. Market studies provide the following forecasts for both products' demand: $40 \% \mathrm{~A}-60 \% \mathrm{~B}, 70 \% \mathrm{~A}-30 \% \mathrm{~B}$, and $100 \% \mathrm{~A}$, with associated probabilities of $30 \%, 40 \%$ and $30 \%$, respectively.

In the revised scenario study, Hertz's approach $[35],{ }^{8}$ instead of Hillier's model [36], has been followed, and the Montecarlo method has been applied. The variables considered have been total demand, quality level, delivery time, an process time for product B. Fig. 4 illustrates the simulation process.

Initial assumptions are that

- these variables are independent, ${ }^{9}$

- yearly cash flows are positive and perfectly correlated,

- production, sales and demand are equal.

(these assumptions can be relaxed if desired in order to simulate different and complementary scenarios).

The "conventional" and "advanced" models cases have been considered separately, and for each cases, 1000 and 10000 simulations have been run. The outcomes of these simulations are shown in Tables $3-6$, respectively.

\footnotetext{
This approach has been recognized as more powerful than Hillier's one, it provides not only the expected mean and standard deviation for the NPV, but its density function, and the probability for NPV $>0$ as well. Moreover, as more different values can be considered for the different variables, and not only their mean value, the outcomes of the model are much more reliable. However, some authors prefer to use Hillier's method, as can be seen in Azzone et al. [37].

${ }^{9}$ As total production for a year will depend on the units demanded per year, the number of A or B items to produce will have to take into account that demand.
}

As can be seen, for the data employed, the acquisition of the "advanced" model seems much more advisable, given that the mean and standard deviation for its NPV are better than those pertaining to the "conventional" model. Consequently, Company $\mathrm{X}$ would benefit from higher profits if it acquires the "advanced" model and (1) costs' estimates for different flexibilities variables are accurate, up-to-date, and reliable, and (2) demand happens to be exactly the same as its forecasts.

Since the situation described is just an example, and a very simple example indeed, the generalisation of conclusions is limited. Nevertheless, in spite of its many shortcomings, it shows that, under conditions of uncertainty, flexible machinery can provide better NPVs than rigid machinery. As numerical results become available, it is possible that the importance of manufacturing flexibility may be acknowledged by skeptical financial managers and accountants.

\subsection{Operational flexibility and cash budgeting}

The short-term budget or cash budget of a firm is the cornerstone of the control of its short-term capital expenditures. In fact, except for firms of very moderate size, some sort of short-term budget appears to be a necessity if management is to control its capital expenditures [30]. Short-term capital expenditures follow from the operating cycle of production requirements. Under operational flexibility, the operating cycle is expected to respond in a timely fashion to changes in plans, programmes and schedules. Such capability may lead to a improved linkage between manufacturing requirements of short-term capital and the forecasted total current liabilities position of the firm as expressed in the firm's balance sheets.

The proposal presented here is an integrated model for the financial justification process, comprising long- and short-term interactions, to be used not only during the pre-acquisition stage, but also on a continuous basis, throughout the life of the investment. Data on each manufacturing or operating cycle yields, as they are affected not only by the changing nature of the market in which a company operates, but by operational flexibility 


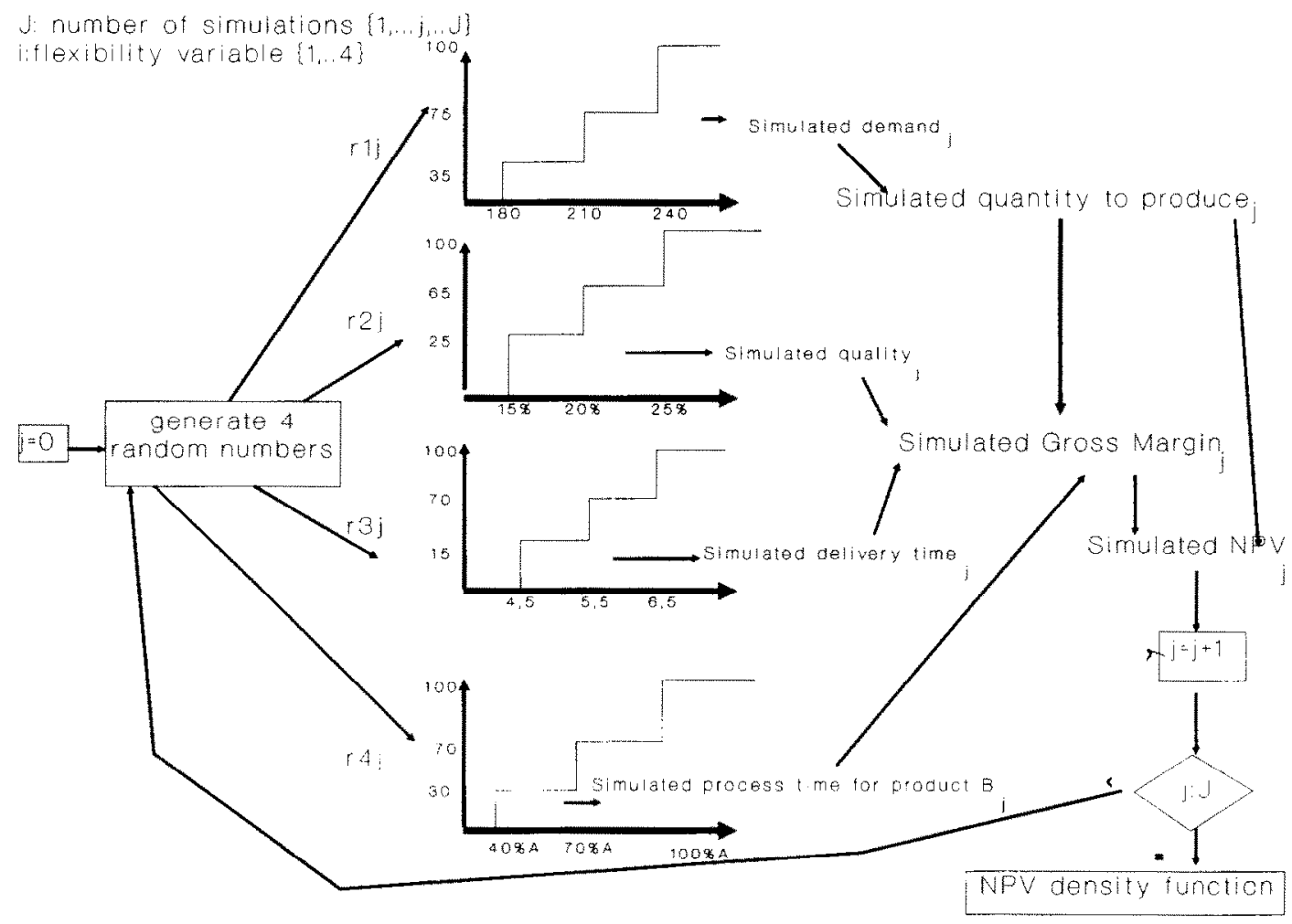

Fig. 4. An illustration of the simulation process.

as well, provide the required feedback for the consecutive revisions.

As was stated in Section 3.2, the outcome of the simulation model proposed will strongly depend on the fitness between (1) the accuracy and reliability of the costs estimates and current costs, and (2) actual demand values and features and forecasted ones. This means that NPV figures are ex-ante figures, which are useful for the decision-making process only, i.e. to select the investment to accomplish, but completely inadequate for both the control of the production process and the monitoring and control of the short-term capital expenditures.

The ex-ante calculated cash flows may differ from current cash flows as changes in the nature and values of demand might take place. Whenever these changes happen to occur, the production process has to be modified in order to accommodate the features of the output to the requirements of the new environment. These adjustments usually lead to cash expenditures which also differ from the forecasted ones. Obviously, the gap between actual and expected expenditures will depend heavily on (1) the acquired design flexibility and its associated operative costs, and (2) the operational flexibility and its associated operative costs.

Costs estimations for different design flexibilities were already done for the calculus of NPV. Operational flexibility associated costs have to be estimated now. It is worth noting that operational flexibility contributes a deal to the smoothing of the production flow. Its effects, although mainly independent of those of the design flexibility, can interact with them, thus providing the company with a superior capability to adapt to shifts in the external environment. The cost estimation process might become a complex one since not only costs for the operational flexibility have to be considered-manufacturing variables to be analysed will be $H, Q, P, Z, \mathrm{AA}$ and $\mathrm{BB}$ - but the estimated ones for the design flexibility as well. 
Table 3

NPV estimates for the "conventional" model and 1000 simulations

\begin{tabular}{|c|c|c|c|}
\hline NPV & Probability & NPV & Probability \\
\hline-975 & $4.3 \%$ & -75 & $2.2 \%$ \\
\hline-950 & 0 & -50 & 0 \\
\hline-925 & 0 & -25 & $1 \%$ \\
\hline-900 & $4 \%$ & 0 & 0 \\
\hline-875 & 0 & +25 & 0 \\
\hline-850 & $2.2 \%$ & +50 & 1 \\
\hline-825 & $1.8 \%$ & +75 & $1.1 \%$ \\
\hline-800 & $2.3 \%$ & +100 & $4 \%$ \\
\hline-785 & $0.5 \%$ & +125 & $2.4 \%$ \\
\hline-750 & 0 & +150 & $2.5 \%$ \\
\hline-725 & 0 & +175 & $0.9 \%$ \\
\hline-700 & 0 & +200 & 0 \\
\hline-675 & 0 & +225 & $2.2 \%$ \\
\hline-650 & $1.3 \%$ & +250 & $2.3 \%$ \\
\hline-625 & $2.8 \%$ & +275 & $1.3 \%$ \\
\hline-600 & $3.8 \%$ & +300 & $2.2 \%$ \\
\hline-575 & $2.9 \%$ & +325 & 0 \\
\hline-550 & 0 & +350 & $5.5 \%$ \\
\hline-525 & 0 & +375 & 0 \\
\hline-500 & $7 \%$ & +400 & 0 \\
\hline-475 & 0 & +425 & $1.6 \%$ \\
\hline-450 & $7 \%$ & +450 & $0.7 \%$ \\
\hline-425 & 0 & +475 & 0 \\
\hline-400 & $1.6 \%$ & +500 & $5.9 \%$ \\
\hline-375 & 0 & +525 & 0 \\
\hline-350 & $4 \%$ & +550 & 0 \\
\hline-325 & $2.9 \%$ & +575 & 0 \\
\hline-300 & $0.1 \%$ & +600 & $0.6 \%$ \\
\hline-275 & $4.9 \%$ & +625 & $0.6 \%$ \\
\hline-250 & 0 & +650 & 0 \\
\hline-225 & $0.5 \%$ & +675 & 1 \\
\hline-200 & 0 & +700 & 0 \\
\hline-175 & $1.5 \%$ & +725 & 0 \\
\hline-150 & 0 & +750 & 0 \\
\hline-125 & $3.4 \%$ & +775 & 0 \\
\hline-100 & $1.6 \%$ & & \\
\hline
\end{tabular}

$\mathrm{E}(\mathrm{NPV})=-181$

$\sigma^{2}(\mathrm{NPV})=434$

An example is provided. Let us suppose that Company X already bought the "advanced" model and the short-term budget for the second year is being elaborated. The information gathered from the revised yearly forecast reveals that there will be an unusual high demand for product $\mathrm{B}$, a delivery time close to 4.5 days, and that total demand will be close to 240 units. Let us suppose now that the advanced model also provides some operational
Table 4

NPV estimates for the "conventional" model and 10000 simulations

\begin{tabular}{|c|c|c|c|}
\hline NPV & Probability & NPV & Probability \\
\hline-975 & $4.17 \%$ & -75 & $1.98 \%$ \\
\hline-950 & 0 & -50 & 0 \\
\hline-925 & 0 & -25 & $1.75 \%$ \\
\hline-900 & $9.6 \%$ & 0 & 0 \\
\hline-875 & 0 & +25 & 0 \\
\hline-850 & $2.16 \%$ & +50 & $1.09 \%$ \\
\hline-825 & $1.5 \%$ & +75 & $1.04 \%$ \\
\hline-800 & $2.31 \%$ & +100 & $3.89 \%$ \\
\hline-785 & $0.5 \%$ & +125 & $2.31 \%$ \\
\hline-750 & 0 & +150 & $3.38 \%$ \\
\hline-725 & 0 & +175 & $0.95 \%$ \\
\hline-700 & 0 & +200 & 0 \\
\hline-675 & 0 & 1225 & $1.91 \%$ \\
\hline-650 & $1.96 \%$ & +250 & $2.13 \%$ \\
\hline-625 & $2.98 \%$ & +275 & $1.21 \%$ \\
\hline-600 & $4.26 \%$ & +300 & $2.4 \% \%$ \\
\hline-575 & $2.52 \%$ & +325 & 0 \\
\hline-550 & 0 & +350 & $4.57 \%$ \\
\hline-525 & 0 & +375 & 0 \\
\hline-500 & $5.98 \%$ & +400 & 0 \\
\hline-475 & 0 & +425 & $1.17 \%$ \\
\hline-450 & $8.04 \%$ & +450 & $1.28 \%$ \\
\hline-425 & 0 & +475 & 0 \\
\hline-400 & $1.58 \%$ & +500 & $4.62 \%$ \\
\hline-375 & 0 & +525 & 0 \\
\hline-350 & $3.9 \%$ & +550 & 0 \\
\hline-325 & $2.5 \%$ & +575 & 0 \\
\hline-300 & $0.3 \%$ & +600 & $0.52 \%$ \\
\hline-275 & $5.61 \%$ & +625 & $0.68 \%$ \\
\hline-250 & 0 & +650 & 0 \\
\hline-225 & $0.7 \%$ & +675 & $1.47 \%$ \\
\hline-200 & 0 & +700 & 0 \\
\hline-175 & $1.6 \%$ & +725 & 0 \\
\hline-150 & 0 & +750 & 0 \\
\hline-125 & $3.22 \%$ & +775 & $0.48 \%$ \\
\hline-100 & $1.82 \%$ & & \\
\hline
\end{tabular}

$\mathrm{E}(\mathrm{NPV})=-190$

$\sigma^{2}(\mathrm{NPV})=433$.

flexibility, for example, $\mathrm{H}$ (the manufacturing system is capable of running virtually unattended during the second and third shift). Accountants and operative managers have facilitated the following cost estimation: if the machine runs unattended during the second shift, total operative costs for that shift may diminish by $35 \%$. If this machine is also able to run unattended during the third shift, total operative costs for that shift may diminish to $65 \%$. 
Table 5

NPV estimates for the "advanced" model and 1.000 simulations

\begin{tabular}{rlrl}
\hline NPV & Probability & NPV & Probability \\
\hline-375 & 0 & +25 & 0 \\
-350 & $8 \%$ & +50 & $4.3 \%$ \\
-325 & $2.9 \%$ & +75 & $9.5 \%$ \\
-300 & $11.3 \%$ & +100 & $9.6 \%$ \\
-275 & 0 & +125 & 0 \\
-250 & $4.2 \%$ & +150 & $1.8 \%$ \\
-225 & 0 & +175 & 0 \\
-200 & 3 & +200 & 9 \\
-175 & 0 & +225 & $4.1 \%$ \\
-150 & 0 & +250 & 7 \\
-125 & 0 & +275 & 0 \\
-100 & 0 & +300 & $2.4 \%$ \\
-75 & 0 & +325 & $4.8 \%$ \\
-50 & $8.5 \%$ & +350 & 0 \\
-25 & 0 & +375 & $2.2 \%$ \\
0 & $4.3 \%$ & +400 & 0 \\
\hline
\end{tabular}

$\mathrm{E}(\mathrm{NPV})=3.77$

$\sigma^{2}(\mathrm{NPV})=227$

Table 6

NPV estimates for the "advanced" model and 10000 simulations

\begin{tabular}{rlll}
\hline NPV & Probability & NPV & Probability \\
\hline-375 & 0 & +25 & 0 \\
-350 & $8 \%$ & +50 & $3.17 \%$ \\
-325 & $2.85 \%$ & +75 & $11.39 \%$ \\
-300 & $10.3 \%$ & +100 & $10.27 \%$ \\
-275 & 0 & +125 & 0 \\
-250 & $3.94 \%$ & +150 & $2.19 \%$ \\
-225 & 0 & +175 & 0 \\
-200 & $7.57 \%$ & +200 & $8.53 \%$ \\
-175 & 0 & +225 & $3.67 \%$ \\
-150 & $2.89 \%$ & +250 & $7.03 \%$ \\
-125 & 0 & +275 & 0 \\
-100 & 0 & +300 & $2.9 \%$ \\
-75 & 0 & +325 & $5.56 \%$ \\
-50 & 0 & +350 & 0 \\
-25 & 0 & +375 & $2.18 \%$ \\
0 & $8.5 \%$ & +400 & 0 \\
\hline
\end{tabular}

$E(N P V)=4.87$,

$\sigma^{2}(\mathrm{NPV})=225$

Company $\mathrm{X}$ operates on a single shift per day basis, this flexibility being neglected so far. However, as a consequence of the fresh information provided by the revised forecast, the firm has to determine which option will be more interesting. The advanced model can be configurated so that it devotes $80 \%$ of its process time to manufacture product $\mathrm{B}$, thus incurring the corresponding associated cost. This adjustment may lead to a certain delay in the production of product $A$, and then, a new cost has to be taken into account, which is the cost of delay. So, two costs have to be considered now. Another option would be to operate during a second shift. For that purpose, the equipment can be reconfigurated so that it devotes $40 \%$ of its process time to the production of B per shift. Assuming that total production of $A$ amounts for $60 \%$ of the process time of the equipment per shift, no delays can be assumed, and, accordingly, no costs for this concept are to be expected. The final decision will depend on the total operative costs of each option which, in turn, will depend heavily on the cost of the delays.

The short-term budgeting process will then be strongly influenced by the final decision adopted, no matter what it has been, since both options' cost differ from the ex-ante estimations. Thus, the operative adjustments will lead to a new cash-flow figure. Observed changes in the manufacturing cycle income and/or outcome levels provided by operational flexibility would also be employed in the re-calculation of the working capital needed.

It is also worth noting that the conceptual framework here suggested helps to avoid one of the most important problems associated with DCF procedures: they are not suitable for the evaluation of the intangible benefits, while flexible technologies explicitly seem to promote and ease the creation of intangible benefits, e.g. technological competencies. Consequently, expected benefits related to these technologies are not likely to be translated into financial variables, nor taken into account for investments appraisals. The model proposed here incorporates the intangible benefits, by means of their referrance to the Operational flexibility, as far as computations of the cash budget may lake them into account.

The financial controller has traditionally played an important role in the evaluation process, especially in the budgeting process and in setting the budget control procedures, in defining the type of financial performance criteria for the different 
responsibility centres, and in developing administrative procedures. The approach here suggested has a different and complementary aim. Shifts in operative variables are likely to change the operative procedures and, consequently, the expected yields of the production process. The financial variables will have to incorporate such changes. Thus, shifts in operative variables show whether the "exante" budget has become unrealistic and it does have to be revised. The difference between this approach and the conventional one is that this revision is driven by the way acted by plant managers and employees, while it has been traditionally accepted that the way financial performance is measured directly affects the way managers act $[38, \mathrm{pp} .4]$.

\section{The early warning system}

The example used in Section 3.2 and 3.3 tries to illustrate how manufacturing variables can be converted into cost figures and then employed for the calculus of the NPV. A simple spreadsheet can be used for that calculus and the obtained figures may be helpful for providing some insight on the profitability of the flexible equipment.

However, this example being a very simplistic one, it does not allow to determine which of the different manufacturing variables have stronger effects on the NPV.

Further explorations are in course in order to identify (1) which flexibility variables influence the NPV for a given market the most, (2) which flexibility variables are more convenient for different markets, and (3) which are the combined effects, if any, of the different flexibilities.

The results of this research are beginning to provide relevant information "ex-ante" on the universe of equipments that a company has to explore, according to the flexibility types they possess, the flexibility that the company already has, the conditions of the market in which the company operates, and the profitability constraints of the company. This universe only includes those equipments whose flexibilities allow the company not only to fulfill its market requirements, but its financial ones as well.

'To this extent, an important change takes place in the role played by performance measurement systems and budgeting techniques: they become tools with a capability to forecast, or, at least, to anticipate, what is likely to happen and why. Proper actions can then be taken before the "damage" is done.

\section{Summary and concluding remarks}

It is the objective of this paper to construct a translation system of manufacturing flexibility in such a way that its related advantages can be assessed both financially and operatively. More specifically, operative/manufacturing variables, are to be considered as the starting points in capital budgeting calculative practices. In short, the proposed approach indicates that a variation/deviation in a performance relevant manufacturing variable has to be valuated and translated into a corresponding variation/deviation of the related financial variable. The latter modification of the financial variables can then be used consequently for the financial and economical justification of the investment in flexibility.

Variation/deviations in the operative variables are grouped and ranked, giving way to an early warning system. It has the implicit advantage of its simplicity: operations and financial managers can concentrate their efforts on the selected variables, thus leading to important savings of management time, i.e. indirect costs.

The simplicity of the approach is also important for other reasons:

(i) It helps the "plant" people (not only management or staff people) to figure out their contribution to the company's profitability while it also allows the "office" people to understand where the strengths and weaknesses of the business are located. Consequently, efforts to improve the plant performance can be profitability oriented and budget allocations and re-allocations can be performed more efficiently.

(ii) The firm can enjoy an increased and more timely capability to respond to potential investment opportunities, given that only relevant variables (being operative or financial ones) are likely to be paid attention to. 
(iii) It helps to avoid the development of complex performance measurement systems whose inherent difficulty may prevent management and employees from being involved in "paralysis by analysis".

(iv) More accurate, updated and reliable estimates of the relevant financial variables are obtained because of:

- the data used, i.e. directly from the daily operations of the company (as far as the manufacturing variables are converted into costs figures)

- no new techniques, nor new capital budgeting models, nor new and/or complex performance measurement systems for flexibility models are suggested, thus avoiding adverse reactions and taking benefit of the skills of the personnel.

(v) It makes it easier to argue that linkages between flexible manufacturing and financial figures can be anticipated by the firm, thus leading to a fresh approach to the financial justification of AMT investments.

(vi) A successful implementation of the system can be expected: it is based upon the conventional capital budgeting techniques, it does not require "advanced knowledge" to deal with it and to understand it.

Other advantages of the suggested translation system are related to the following:

\section{I. Sensitivity analysis}

The response of the financial variables to shifts in the manufacturing variables can be obtained from simulation studies. The outcome can be used to determine how much flexibility the firm can financially afford itself, and how much the firm is willing to pay for different levels of flexibility.

\subsection{Inexpensive system}

It does not need additional expenditure during the implementation phase, or during its operational time. It does not need to stop the firm activities, or even to develop pilot studies. Furthermore, common software appliances, such as spreadsheets, can be used for the computations of the revised financial variables.

\subsection{Capital investment tool for both financial and operational management}

They are able to participate proactively in the strategic decision-making process of the firm because they have access to capital investment information, i.e. the likely outcomes of the investments in flexible technologies.

\section{Suggestions for future research}

Much research remains to be done before all the cited advantages of the approach suggested here can be realized. First, the validity of the proposed classification of flexibilities types into design and operational flexibility, as indicative of the longterm and short-term decisions associated with flexibility, has to be tested. Second, the suitability of conventional capital budgeting techniques for the appraisal of flexible technology investments has also to be tested. Third, all the implicit assumptions concerning the linkages between operative variables and financial variables have to be tested empirically. Fourth, the combined effects of different flexibilities have not been assessed as yet, so it has been assumed that these effects were independent. Fifth, the suggested early warning system is still in process, so no concluding guidelines on what types of flexibility influence the profitability of the investments the most can be suggested. There is also another important reason for the urgent need of developing a refined early warning system, i.e. the decision makers may try to influence the cost figures associated to the operative/manufacturing flexibility variables, thus leading to biased changes of the financial variables. This has been the common situation under conventional approaches. One solution can be to involve more people in the process, belonging to different levels of the hierarchy, other than strictly related to "plant" level as suggested here. However, this solution will likely lead to higher complexity while higher accuracy cannot be granted: further research is imperatively needed to 
deal with this point. No solution has as yet been proposed to solve this problem. As Nanni et al. [39] note, it is more useful for the data to be approximate and relevant than precise but irrelevant. According to this remark, a strong effort is needed to identify the different factors leading the valuation factors so that, at least relevant values can be obtained in spite of their inaccuracy.

The sixth point to solve is the one related to the fact that it has been implicitly assumed that the existing financial situation of the company is irrelevant, for the sake of simplicity. This assumption is obviously wrong, since capital losses due to the use of the existing rigid systems of the company under changing conditions may lead to shortages in long- and short-term finan- cial sourcing. These shortages alter the budgetary and profitability constrains, reducing the investments' options and, thereby, the universe of equipments to consider the types and degrees of flexibilities which can be acquired. If this is the case, i.e. rigid equipments are generating capital losses, the best option for the company should be to eliminate these equipments and replace them for flexible ones. However, this option may become a mousetrap since it is not always feasible, easy, and cheap, to change radically the production process. And, if these three circumstances were to exist, a new handicap would have to be overcome: the company would likely lack the financial resources needed. It is quite difficult to find a reasonable solution for the whole problem that not only goes far away from the scope of this article, but also opens new avenues for future research as well.

In spite of the many shortcomings of this approach, the theoretical assumptions upon which it is based might be considered worthwhile, making it a starting point for further research efforts. It should be noted that the above system, as it has been conceived, might easily become a test for itself. If the assumptions on which the system is based are wrong, the outcome will be a far cry from actual operational numbers. ${ }^{10}$

\footnotetext{
${ }^{10}$ Comments from Hanno Roberts and Alejandro Balbás are gratefully acknowledged. I thank the referees for their detailed comments, which contributed to considerable improvements in this paper.
}

\section{References}

[1] Stecke, K.E. and Raman, N., 1986. Production Flexibilities and their Impact on Manufacturing Strategy. Working Paper No. 484., Graduate School of Business Administration, University of Michigan, Ann Arbor.

[2] Hayes, R.H. and Wheelwright, S.C., 1984. Restoring Our Competitive Edge: Competing Through Manufacturing. Wiley, New York.

[3] Ettlie, J.E., 1988. Implementation Strategies for Discrete Part Manufacturing Technologies. University of Michigan, Ann Arbor.

[4] Ramasesh, R.V. and Jayakumar, M.D., 1991. Measurement of manufacturing flexibility: A value based approach. J. Oper. Mgmt., 10(4): 446-465.

[5] Gerwin, D. and Kolodny, H., 1992. Management of advanced manufacturing technology: Strategy, organization \& innovation, in: Dundar F. Kocaoglu (Ed.), Wiley series in Engineering and Technology Management, Wilcy, Ncw York. pp. $21-41$.

[6] Child, J., 1972. Organizational structure, environment and performance: The role of strategic choice. Sociology, 6: $1-22$.

[7] Skinner, W., 1985. Manufacturing: The formidable competitive weapon. Wiley, New York.

[8] Swamidass, P.M., 1988. Manufacturing Flexibility. Monograph No. 2, Texas Operations Management Association.

[9] Zelenovic, D., 1992. Flexibility: A condition for effective production systems. Int. J. Prod. Res., 20(3): 319-337.

[10] Cox, T., 1989. Toward the measurement of manufacturing flexibility. Prod. Inventory Mgmt. J., 68-72.

[11] Miller, J.G. and Roth, A.V., 1987. Manufacturing strategies. Executive Summary of the 1987 North American Manufacturing Futures Survey, Boston University, Boston.

[12] Miller and Kim, 1990. Beyond the quality revolution: U.S. Manufacturing strategy in the 1990s. Research Report of the Boston University Manufacturing Roundtable.

[13] Sethi, A.K. and Sethi, S.P., 1990. Flexibility in manufacturing: A survey. Int. J. Flexible Manuf. Systems, 2(4): 289-328.

[14] Dixon, J.R., 1992. Measuring manufacturing flexibility: An empirical investigation. Eur. J. Oper. Res., 60: 131-143.

[15] Kumar, V., 1987. Entropic measures of manufacturing flexibility. Int. J. Production Res., 25(7): 957-966.

[16] Brill, P. and Mandelbaum, M., 1989. On measures of flexibility in manufacturing systems. Omega, 14(6): 465-473.

[17] Gupta, Y.P. and Somers, T.M. 1992. The measurement of manufacturing flexibility. Eur. J. Oper. Res., 60: 166-182.

[18] Gerwin, D., 1982. Do's and don'ts of computerized manufacturing. Har. Bus. Rev., March-April, 107-116.

[19] Carter, M.F., 1986. Designing flexibility into automated manufacturing systems. Proc. 2nd ORSA/RIMS Conf. Flexible Manufacturing Systems. Ann Arbor, pp 107-118.

[20] Bernardo, J.J. and Mohamed, Z., 1992. The measurement and use of operational flexibility in the loading of 
flexible manufacturing systems. Eur. J. Oper. Res., 60: 144-155.

[21] Adler, P., 1988. Managing flexible automation. Cal. Mgmt. Rev., 30: 34-56.

[22] Lefley, F. and Wharton, F., 1993. Advanced manufacturing technology investment appraisal: A survey of UK manufacturing companies. Proc. 4th Internat. Production Management Conf., London, pp. 369-382.

[23] Meredith, J.R. and Hill, M.M., 1987. Justifying new manufacturing systems: A managerial approach. Sloan Mgmt. Rev., 49-61.

[24] Berliner, C., Hendricks, D.A., Keys, D.E. and Rudnicky, E.J., 1987. Cost Accounting for Factory Automation. National Association of Accountants, Montvale.

[25] Alvarez-Gil, M.J. and Roberts, H.J.E., 1993. The financial implications of lean production. Proc. 4th Internat. Production Management Conf., London, pp. 11-28.

[26] Kulatilaka, N., 1988. Valuing the flexibility of flexible manufacturing systems. IEEE Trans. Eng. Mgmt., 35(4): 250-257.

[27] Gold, B., 1982. Revising managerial evaluations of computer-aided manufacturing systems. Proc. Autofact Western Conference, Dearborn, Society of Manufacturing Engineers, MI, pp. 157-169

[28] Kaplan, K.S., 1990. Limitations of cost accounting in advanced manufacturing environments, in: Robert $S$. Kaplan (Ed.), Measures for Manufacturing Excellence, Harvard Business School Press, Boston: pp. 15-38.

[29] Nanni, A.J., 1993. Developing a process for changing performance measurement. Paper presented at The International Seminar on Manufacturing Accounting Research, Eindhoven. The Netherlands, May 16-19, Paper No. 21, p. 7,8 .

[30] Tayles, M. and Drury, C, 1993. New manufacturing technologies and management accounting systems: Some evidence of the perceptions of UK management accounting practitioners. Paper presented at The International Seminar on Manufacturing Accounting Research. Eindhoven, The Netherlands, May 16-19, Paper No. 16.

[31] Berliner, C. and Brimson, J.A., (Eds)., 1987. Cost Management for Today's Advanced Manufacturing: The CAM-I Conceptual Design. Harvard Business School Press, Boston.

[32] Noori, H., 1990. Managing the Dynamics of new Technology: Issues in Manufacturing Management. PrenticeHall, Englewood Cliffs, NJ, pp. 192-221.

[33] Levy, H. and Sarnat. M., 1990. Capital Investments and Financial Decisions. 4th edn, Prentice-Hall International (UK) Ltd., p. 24.

[34] Szendrovits, A.Z. and Truscott, W.G., 1989. Fundamentals of scheduling: The manufacturing cycle time, in: R. Wild (Ed.), International Handbook of Production and Operations Management, Cassel Educational Limited, London.

[35] Hertz, D.R., 1964. Risk analysis in capital investment. Har. Bus. Rev., 42(1): 95-106.

[36] Hillier, F.S., 1963. The derivation of probabilistic information for the evaluation of risky investments. Mgmt. Sci. 9(3): 443-457.

[37] Azzone, G., Bertele, U. and Masella, C., 1992. Strategic management and financial accounting: An option based approach. Proc. 15th Ann. Congr of the European Accounting Association. Madrid, 22-24 April.

[38] Bruggeman, W. and Van der Stede, W., 1993. Fitting management control systems to the competitive advantage. Proc. Internat. Seminar on Manufacturing Research. Eindhoven, The Netherlands, May 16-19, Paper No. 2.

[39] Nanni, Miller and Vollman, 1987. What we shall account for?. Mgmt. Acc., 42-48, p. 48. 